\title{
Trabalho de conclusão de curso: tempo-espaço formativo
}

\author{
Ilma Passos Alencastro Veiga ${ }^{1}$ \\ Marlene Emília Pinheiro de Lemos ${ }^{2}$ \\ Neuza Garbin ${ }^{3}$
}

\section{Resumo}

O estudo focaliza a importância do Trabalho de Conclusão de Curso TCC, - como um exercício acadêmico correlacionado à área de formação dos alunos de nível superior, realizado em um momento do curso. É uma atividade curricular obrigatória, de natureza científica na área de conhecimento que fundamenta o curso de graduação a que estiver vinculado. O TCC é uma atividade de pesquisa que significa dialogar com a realidade de forma organizada e objetiva, a fim de dar respostas aos problemas reais. Professores e alunos, ao desenvolverem investigações de conclusão de curso, precisam ter consciência das questões éticas de todo processo.

Palavras-chave: Formação acadêmica. Trabalho de conclusão de curso. Pesquisa.

\section{Introdução}

Neste estudo, procuramos enfatizar o Trabalho de Conclusão de Curso (TCC) como um exercício acadêmico correlacionado à área de formação do aluno de nível superior, realizado em um momento particular de seu curso.

Aqui, encontram-se alguns elementos indispensáveis à compreensão do assunto. Inicialmente, propusemo-nos a investigar os enfoques conceituais de TCC presentes em diversas fontes de pesquisa. A seguir, ampliamos os estudos para

1 Licenciada em Pedagogia, Doutora em Educação, UniCEUB, Curso Pedagogia. ipaveiga@ terra.com.br.

2 Mestre em Educação, UniCEUB, Curso Pedagogia. marlenemilia@gmail.com.

3 Licenciada em Pedagogia - Especialista em Docência do Ensino Superior, UniCEUB, e em Avaliação a Distância, UNB, Curso Pedagogia. neuzagarbin@brturbo.com.br. 
questões pertinentes à realização do trabalho, nele incluindo, além dos significados de ciência e de pesquisa, reflexões a respeito da ética e da pesquisa e orientações metodológicas, necessárias à construção de um projeto. A esses aspectos, acrescentamos contribuições para o processo de orientação da pesquisa sob a ótica das relações orientador-orientando.

A concepção de ciência, tratada sob uma perspectiva contemporânea, com ênfase na dimensão social, apoia-se no pensamento de Demo (1985), para quem a ciência está em constante movimento e o processo investigativo ocorre de forma contínua e sistematizada. A este, soma-se o posicionamento de Santos (1989), que rompe com a hierarquização entre o conhecimento científico e o conhecimento vulgar do senso comum e apresenta quatro proposições que sustentam a sua tese de não dualidade do conhecimento. Os estudos referentes ao significado de pesquisa se apresentam enriquecidos com as qualidades que constituem a pesquisa e sua tipologia (bibliográfica, de campo e de laboratório). No tratamento do tema a ética e a pesquisa, ressaltamos os cuidados exigidos de professores e alunos, na condução do trabalho, de forma a não transgredir normas dos Comitês de Ética institucionais. Em métodos e técnicas de pesquisa, chamamos a atenção para a interdependência entre o método (caminho, arcabouço teórico) e a visão de mundo do pesquisador e para a finalidade das técnicas (viabilizar o método). Tomando por base o caráter de um projeto de pesquisa, elencamos os componentes de sua organização e os elementos que compõem a estrutura do relatório. Por fim, abordamos a importância do relacionamento orientador/orientando e suas atribuições na produção do trabalho de pesquisa.

\section{Trabalho de conclusão de curso}

Etapa importante na conclusão da graduação, o Trabalho de Conclusão de Curso é amplamente utilizado como trabalho científico relacionado à área de formação do aluno. Embasados nos estudos de autores diversos, a respeito do componente curricular Trabalho de Conclusão de Curso (TCC), observamos que, de forma contundente, as ideias contidas na literatura específica apresentam-se compartilhadas e ao mesmo tempo convergentes, quando se referem aos elementos conceituais que definem e explicam o TCC. 
As exigências institucionais, quanto à apresentação de um trabalho de natureza científica em área específica do conhecimento, resultam não somente em experiência acadêmica enriquecedora para o aluno, mas, também, em indicador de qualidade institucional, ao mesmo tempo em que oferecem informações pertinentes ao progresso científico e tecnológico e contribuem para a solução de problemas sociais.

O Trabalho de Conclusão de Curso sinaliza a possibilidade de o aluno consolidar ou aprofundar os conhecimentos acumulados durante a sua formação, descobrir respostas para questões relacionadas às diversas áreas do conhecimento, inventar novas técnicas e criar novos produtos que a sociedade necessita e valoriza, ao desenvolver a pesquisa de temas de seu interesse, por vezes enriquecido por assuntos circundantes a ele.

Veiga (2007, p. 144) afirma que "[...] o trabalho de conclusão de curso (TCC) é atividade para os acadêmicos concluintes dos cursos de formação [...] podendo ser desenvolvido a partir da segunda metade do curso, observando as exigências constantes nas normas". Segundo a autora, "[...] o objetivo principal do TCC no curso é estimular a capacidade investigativa e elaborar um trabalho científico, bem como partilhar as atividades de uma experiência de pesquisa contribuindo com a formação profissional”.

A natureza da questão desencadeadora do processo de pesquisa pode caracterizar-se como necessidade intelectual ou dificuldade percebida na prática profissional. $\mathrm{O}$ avanço no processo de construção de qualquer área do conhecimento exige que a prática seja constantemente objeto de pesquisa.

Na visão de Severino (2008, p. 202), o Trabalho de Conclusão de Curso:

[...] deve ser entendido e praticado como um trabalho científico. Pode ser um trabalho teórico, documental ou de campo. Quaisquer que sejam as perspectivas de abordagem, a atividade visa articular e consolidar o processo formativo do aluno pela construção do conhecimento científico em sua área. 
Como trabalho científico, o TCC deve submeter-se aos padrões exigidos para esse tipo de produção e desenvolver-se em três etapas: a elaboração do projeto; a sua execução, na forma de investigação, valendo-se de métodos e técnicas que incluam pertinência, consistência, definição de categorias, análise e interpretação de dados, e no caso de pesquisa quantitativa, manipulação de variáveis e de hipóteses, mensuração de dados; e a síntese do trabalho, ou seja, a conclusão.

O TCC torna-se eficiente recurso para o desenvolvimento da pesquisa na área de formação do aluno. A escolha do tema e do referencial teórico corresponde à dimensão teórica da pesquisa, enquanto a dimensão afetiva se revela pelo envolvimento do aluno com o tema escolhido.

Ao fazermos aproximações dos diversos significados de TCC, concluímos que:

- constitui momento de potencialização e sistematização dos conhecimentos adquiridos ao longo da graduação;

- sinaliza a competência do acadêmico-pesquisador, ao demonstrar autonomia na busca de aprofundamento dos seus conhecimentos;

- possibilita o domínio das bases norteadoras da profissão e da realidade social;

- é um trabalho acadêmico de natureza técnico-científica e condição para obter o diploma de graduação;

- contribui para a autoavaliação institucional quanto à produção do aluno, para reavaliar o trabalho desenvolvido nos seus diversos segmentos.

É importante ressaltar que, embora a monografia, o artigo científico e o ensaio teórico sejam opções frequentes em TCC, outras modalidades podem ser empregadas com a finalidade de articular e consolidar o processo formativo do aluno pela construção do conhecimento científico em sua área.

Veiga (2007, p. 115) apresenta um rol de possibilidades que inclui as modalidades:

[...] monografia é a construção teórica sobre um tema na área específica, embasada em um plano de pesquisa, 
visando à possibilidade de concretização nas seguintes linguagens: televisão; rádio; impresso; on line; fotografia [...] discussão de caso clínico enriquecido de casuística clínica documental e/ou bibliográfica ou ainda relatório que tenha como referência um trabalho de iniciação científica; [...] projeto técnico ou profissional; portfólio...

Diante da riqueza de possibilidades, conclui-se que a instituição de ensino, ao definir as normas para regulamentação de TCC, deve considerar a Proposta Pedagógica e os Projetos Pedagógicos dos cursos, dando liberdade aos colegiados para a escolha da modalidade da área de formação, sem perder o foco de que o aluno, na contemporaneidade, vive em uma sociedade tecnológica, multimídia e globalizada.

\section{Questões pertinentes à realização do TCC}

Este item foi orientado por tríplice preocupação. Primeiramente, responder de maneira simples e acessível à pergunta sobre o que é ciência. Em segundo lugar, discutir de forma breve o significado da pesquisa. Em terceiro lugar, situar a dimensão fundante da ética nos trabalhos acadêmicos.

\subsection{0 que é Ciência?}

O termo ciência pode ser entendido em duas acepções: lato sensu tem o significado de conhecimento; stricto sensu "[...] não se refere a um conhecimento qualquer, mas àquele que, além de apreender ou registrar fatos, os demonstra pelas suas causas constitutivas ou determinantes" (LAKATOS; MARCONI, 1991, p. 20).

A natureza da ciência pode ser compreendida por meio de duas dimensões, na realidade, inseparáveis:

- a compreensiva (contextual ou de conteúdo);

- a metodológica (operacional), abrangendo tanto aspectos lógicos quanto técnicos, ou seja, o método e os procedimentos 
metodológicos que indicam a melhor maneira de desenvolver o processo de interpretação e explicação dos fenômenos que se pretende estudar, analisar, interpretar ou compreender.

Neste estudo, vamos destacar a concepção de ciência sob a perspectiva contemporânea, com ênfase na dimensão social. Isso exige, fundamentalmente, a concepção de conhecimento que contemple a complexidade e a visão plural dos fatos e dos acontecimentos. Enfim, trata-se de aspecto epistemológico.

Vários autores escreveram sobre as concepções e os propósitos da ciência como, por exemplo, Demo (1985), Santos (1989), entre outros. De acordo com Demo (1985, p. 29), a ciência:

[...] um fenômeno histórico, é propriamente um processo. $\mathrm{O}$ conceito de processo traduz as características de uma realidade sempre volúvel, mutável, contraditória, nunca acabada, vir-a ser. Não há estação final onde este trem poderia parar; não há um ponto de chegada onde não tivéssemos que partir. Em ciência estamos começando de novo.

Sob essa ótica, a ciência é um processo em constante movimento e constitui-se em um conjunto de proposições e enunciados que permitem a interpretação e a explicação dos fenômenos. É a busca contínua de novas descobertas, de novas possibilidades de explicações e soluções, de reformulações e de verdades sobre os fenômenos naturais, sociais e humanos. Nesse sentido, a ciência realiza-se por meio do processo investigativo sistemático, com o emprego de métodos e técnicas especificas e não por um conjunto de procedimentos desarticulados entre si.

Para Santos (1989), a ciência é um ato humano, historicamente situado, que admite a não neutralidade e coloca em destaque a questão da intencionalidade. $\mathrm{O}$ autor atribui à ciência uma dimensão utópica e libertadora, que pode ser ampliada pelo diálogo entre os destinatários e os detentores do conhecimento científico.

Sob essa perspectiva, a ciência é analógica, seu estilo não é unidimensional, mas uma configuração de estilos construídos segundo o critério e a imaginação pessoal do cientista, fundamentando-se em quatro proposições: 
a) todo conhecimento científico natural é científico-social;

b) todo conhecimento é local e total;

c) todo conhecimento é autoconhecimento; e

d) todo conhecimento científico visa a constituir-se em senso comum.

De acordo com essas quatro proposições, o conhecimento tende a ser não dualista na medida em que se funda na superação das distinções: natureza e cultura, natural e artificial, vivo e inanimado, mente e matéria, observador e observado (SANTOS, 1995). Essa superação leva o autor a estabelecer vínculo orgânico entre ciências naturais e ciências sociais. É um conhecimento sob condições de possibilidades; constitui-se em pluralidade metodológica, é permitido por meio de um conjunto de temas, cujo objeto se amplia pela interface com outros. O conhecimento, assim configurado, torna-se autoconhecimento, porque tenta dialogar com o senso comum, antes considerado superficial e ilusório. Dessa forma, a ciência realiza a reconfiguração dos saberes, ou seja, a ruptura inovadora do conhecimento científico, evitando a distinção hierárquica entre conhecimento científico e conhecimento vulgar de senso comum. O salto é dado do conhecimento científico ao senso comum, visando a sua reconfiguração.

\subsection{Pesquisa: qual o seu significado?}

O objeto do conhecimento é produto da atividade humana e como tal - não como mero objeto de contemplação - é conhecimento pelo homem (VASQUEZ, 1977, p. 20).

Tomando como referência a epígrafe, podemos afirmar que a pesquisa, em primeiro lugar, é uma atividade humana. É uma das mais importantes manifestações do homem, uma vez que suas descobertas têm contribuído para as transformações do mundo. A pesquisa é, portanto, fruto das condições humanas e históricas. Em outras palavras, para que algo seja significativo como trabalho de investigação deve refletir as qualidades que constituem a pesquisa, quais sejam: 
a) vinculada a um conjunto de valores, concepções de homem, de educação e de sociedade;

b) contextualizada, por estar inserida em determinado contexto histórico, social, político, cultural e educacional;

c) intencional, pois constrói um conhecimento ou um conjunto de conhecimentos que possibilita compreender e transformar a realidade e orientar as ações prepositivas;

d) voltada para a solução de problemas como atividade de busca, questionamento e investigação;

e) sistemática, isto é, não pode ser improvisada, casual, nem arbitrária;

f) mobilizadora da inteligência, do espírito inquiridor, dos processos de produção do conhecimento, pois estimula os alunos a interpretar criticamente o que aprendem;

g) alicerçada no princípio da totalidade, pois fortalece os conhecimentos relevantes.

A pesquisa contribui para melhorar o ensino, a formação do aluno e para construir a crítica do processo educativo como meio de produzir novos conhecimentos. Por outro lado, é o elo articulador do envolvimento de alunos e professor na atividade investigativa, propiciando, simultaneamente, formação e desenvolvimento profissional. Isso, “[...] além de possibilitar uma iniciação teórico-metodológica eficaz, motiva o educando para a prática da pesquisa e para o rigor acadêmico" (INÁCIO FILHO, 2003, p. 53).

Pesquisa significa, então, indagar, inquirir os fenômenos com o objetivo de compreendê-los e especificá-los, buscando a solução dos problemas detectados. Significa dialogar com a realidade de forma organizada, sistemática e objetiva a fim de dar respostas aos problemas reais.

Para se ter o qualificativo de científico, a pesquisa deve: empregar método adequado à natureza do problema; aplicar procedimentos específicos; estar voltada para a realidade empírica, ou seja, “[...] tudo que existe e pode ser conhecido através da experiência revelada por meio de fatos" (RUDIO, 1986, p. 10); apresentar formas diversificadas de comunicar o conhecimento produzido. 
É a atividade que vai permitir “[...] elaborar um conhecimento, ou um conjunto de conhecimentos, que nos auxilie na compreensão desta realidade e nos oriente em nossas ações" (PÁDUA, 1996, p. 29). Essa atividade deve ter início desde os primeiros semestres da graduação, nos trabalhos de pesquisa, individuais ou em grupo, que cada componente curricular propõe, e, nos semestres finais, quando da elaboração do Trabalho de Conclusão de Curso (TCC), momento do aprofundamento teórico-prático das questões investigadas.

Vale destacar que muitos autores têm procurado organizar uma tipologia para as atividades de pesquisa, considerando diferentes critérios e enfoques, tais como:

[...] os campos da atividade humana (multidisciplinares/interdisciplinares), a utilização dos resultados (pura/ aplicada), segundo as técnicas e instrumentos de observação (direta-participantes/não-participante ou indireta-questionários) entrevistas ou ainda quanto ao 'material' utilizado em sua elaboração (bibliográfica/ documental) (PÁDUA, 1996, p. 32).

De acordo com Inácio Filho (2003), uma pesquisa pode ser: bibliográfica, de campo ou de laboratório (experimental). Apresentamos sinteticamente a tipologia proposta pelo autor:

a) a bibliográfica trabalha com textos, livros, artigos de periódicos, jornais, manuscritos. Utiliza como procedimento a análise documental;

b) a de campo ocorre com o emprego da pesquisa-ação, pesquisaparticipante, estudo de caso e não dispensa a revisão bibliográfica. Requer um ou mais procedimentos de coleta de dados: questionário, formulário, entrevista, observação, grupo focal etc;

c) a de laboratório é aquela em que ocorre experimentação. Também requer a busca da fundamentação teórica e da prática para a discussão do fenômeno a ser investigado. Emprega procedimentos de coleta de dados adequados ao campo científico no âmbito do qual ocorre a investigação.

O conhecimento e o conhecer não se realizam no vazio intelectual, teórico ou prático. Barros e Lehfeld explicitam, com muita clareza, que a pesquisa “[...] é 
o esforço dirigido para a aquisição de determinado conhecimento, que propicia a solução de problemas teóricos, práticos e ou operativos; mesmo quando situados no contexto do dia-a-dia do homem" (1990, p. 27). Dessa forma, o fenômeno a ser interpretado pelo processo investigativo deve considerar a viabilidade metodológica e a disponibilidade das técnicas adequadas ao seu estudo.

\section{A ética e a pesquisa}

A formação do aluno deve ser organizada de acordo com o que se pretende atingir: a pessoa, o cidadão, o profissional. Trata-se de formação ética e, por sua natureza, é um processo longo e complexo. A ética na pesquisa é fonte de orientação para o agir cotidiano de professor e alunos e, para tanto, exige mecanismos de proteção, a fim de evitar algum tipo de dano. Isso leva as instituições de educação superior à criação e à implementação de comitês de ética que definem diretrizes sobre a conduta da pesquisa. Lankshean e Knobel (2008) enfatizam que vincular a ética ao ensino e à pesquisa ajuda a identificar critérios e princípios a serem seguidos pelos professores-pesquisadores, ao conduzirem as investigações. Entre esses princípios, os autores incluem: “[...] ter um projeto de pesquisa válido; obter consentimento informado; evitar omissão; minimizar o risco de danos; demonstrar respeito; evitar coerção ou manipulação; reciprocidade” (LANKSHEAN; KNOBEL, 2008, p. 95). A ética é uma dimensão estruturante do trabalho investigativo.

Professores e alunos, ao desenvolverem projetos investigativos e de conclusão de curso, precisam ter consciência das questões éticas intrínsecas ao projeto e levá-las em consideração desde o momento da concepção. Isso significa que as questões éticas permeiam todo o processo.

Para tratar de ética na pesquisa, é necessário que exploremos as características dessa dimensão. Quando se fala em ética na educação, fala-se em moral, que se define como "[...] um conjunto de valores, regras, normas que dirigem as ações dos individuos na sociedade, ao passo que a ética se apresenta como uma reflexão crítica sobre a moralidade” (RIOS, 2008, p. 81). A moral está sempre presente nas 
ações e relações dos indivíduos ou grupos. Temos a conduta moral quando nos posicionamos em relação a uma determinação social. Agimos moralmente, dizendo sim ou não, obedecendo ou desobedecendo, cumprindo ou não cumprindo. A moral, do latim mos, moris, é uma maneira de agir e, etimologicamente, refere-se a costumes. A ética, por sua vez, “[...] é a reflexão sobre o ato moral, é a forma de fundamentar, legitimar, as ações morais intersubjetivas” (SILVEIRA, 1992, p. 61). Nesse sentido, vale indagar: é possível pensar a pesquisa sem referência ética? Não, pois a ética reflete sobre o que se deve fazer em perspectiva coletiva e não puramente individual.

Os projetos de pesquisa que envolvem seres humanos devem cumprir exigências éticas gerais, as ligadas à área de formação e aos aspectos específicos, tais como estão especificados na Resolução 196/96 do Conselho Nacional de Saúde. Ao elaborar o projeto de pesquisa envolvendo sujeitos humanos, o pesquisador deve pautar-se nas orientações dessa Resolução, uma vez que seu projeto passará por apreciação do Comitê de Ética da instituição (SEVERINO, 2008).

De acordo com as orientações da Resolução (Resolução, 196/96, CNS), a eticidade da pesquisa implica os seguintes quesitos:

a) autonomia: consentimento livre e esclarecido dos indivíduos-alvo e proteção a grupos vulneráveis e a legalmente incapazes, de modo que sejam tratados com dignidade e respeito em sua autonomia;

b) beneficência: ponderação entre riscos e benefícios, tanto atuais como potenciais, individuais ou coletivos, comprometendo-se com o máximo de benefícios e o mínimo de danos e riscos;

c) não maleficência: garantir que danos previsíveis serão evitados;

d) justiça e equidade: fundamento na relevância social da pesquisa.

\section{Delineando os métodos e técnicas de pesquisa}

A discussão em torno do método refere-se à teoria do conhecimento. A produção do conhecimento é processual, histórica, individual e coletiva ao mesmo tempo, não linear nem neutra. Há a disposição dos cientistas para a superação do 
cientificismo. O que interessa é o fenômeno multidimensional. Como afirma Morin (1989, p. 35), “Tudo o que é humano é ao mesmo tempo psíquico, sociológico e econômico, histórico, demográfico".

O método é intrínseco a toda pesquisa científica e, portanto, da ciência e constitui-se em: processo que possibilita a compreensão do fenômeno estudado; caminho que se deve percorrer para chegar aos resultados previstos. O método é caracterizado por dois momentos: "Vai-se do empírico ao concreto pela mediação do abstrato, da sincrese à síntese pela mediação da análise” (INÁCIO FILHO, 2003, p. 151). Esses dois momentos caracterizam o movimento da construção conhecimento.

O método possui na sua organicidade uma lógica interna, conceitos próprios. Sua articulação conceitual tem fundamento na visão de mundo do pesquisador. "Nesse sentido, o método é um caminho, um arcabouço teórico, a partir do qual analisamos os fenômenos" (INÁCIO FILHO, 2003). O método não pode ser reduzido a simples aplicação de procedimentos e de técnicas. A questão dos procedimentos é de ordem instrumental, portanto, referente à prática investigativa, “[...] como um conjunto de técnicas que permitem o desenvolvimento desta atividade nos diferentes momentos do seu processo" (PÁDUA, 1996, p. 30).

A técnica é o recurso que possibilita e viabiliza o método. Para Oliveira (1997, p. 58), “[...] a técnica é a parte material, é a parte prática pela qual se desenvolve a habilidade de ensinar, aprender, produzir, descobrir e inventar" (grifo nosso). A técnica é tecida e envolvida por determinadas finalidades e ideais educativos e tem, propriamente, um caráter de sublimação aos fins (ARAÚJO, 2006).

\section{A organização do Trabalho de Conclusão de Curso}

O projeto é uma proposta de solução do problema, ou seja, da identificação de necessidade a ser atendida. Toda modalidade que trabalha com pesquisa exigirá um procedimento anterior ao trabalho propriamente dito: o pré-projeto. Embora os projetos tenham características em comum, serão discutidos, neste item, os projetos de pesquisa apresentados para a elaboração de trabalhos técnico-científicos. 
O projeto não chega pronto. Ele deve ser concebido, organizado, aprimorado, avaliado. Ter um projeto de boa qualidade "[...] é parte de um compromisso ético, dos deveres do pesquisador com a pesquisa" (LANKSHEAR; KNOBEL, 2008, p. 36). Os autores apresentam o desenvolvimento de um projeto de pesquisa, sinteticamente, enunciados, a seguir:

a) deve ser edificado sobre problema e questões claros e concisamente estruturados;

b) é guiado por estruturas teóricas e conceituais que esclarecem as questões;

c) deve conter estratégia para coleta e organização dos dados;

d) além disso, há necessidade de uma estratégia para análise dos dados; e

e) deve conter estratégia para interpretar e analisar os dados (LANKSHEAR; KNOBEL, 2008).

Vale salientar que todos os componentes do projeto de pesquisa devem estar articulados de maneira coerente, como na Figura 1.

Figura 1. Diagrama dos componentes do projeto de pesquisa.
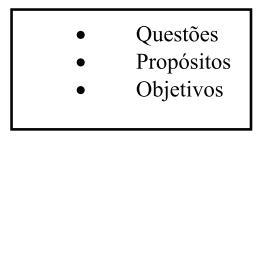

Estrutura teórica

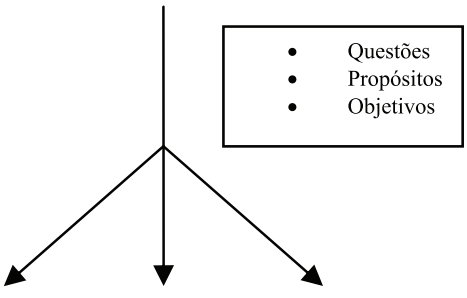

Ideias, exemplos, indícios, modelos, etc. (a serem usados no estudo)

Fonte: Lankshear; Knobel (2008).

Para obter um projeto de pesquisa viável, exequível, a qualidade de nossa investigação dependerá da competência e da responsabilidade com que desenvolvemos cada componente de maneira lógica e coerente. A seguir, apresentamos a organização estrutural do relato final. Cabe destacar a observação de Lankshear e Knobel (2008, p. 305): 
Quando relatamos o nosso estudo devemos tomar o cuidado de fazê-lo de maneira que comuniquem aos leitores que o estudo é coerente, as interpretações são justificadas, os dados são suficientes para tratar com a questão da pesquisa, as representações das pessoas, dos processos e de outros fenômenos são justas e assim por diante.

A elaboração do relatório final da pesquisa ou do trabalho de conclusão de curso não deve ser entendida como o mero cumprimento de formalidade burocrática ou tarefa obrigatória de integralização curricular para obtenção de um título. Ao contrário, isso representa o início de maturidade intelectual. Inácio Filho (2003, p. 127) esclarece que

Quando se escreve um texto, seja ele científico ou não, deve-se sempre ter em conta que se está num processo de comunicação, isto é, tem-se uma mensagem a ser comunicada (o texto), um emissor que é quem elabora (ou transmite) a mensagem, um canal de comunicação. [...].

O relatório de pesquisa, portanto, nada mais é que o relato escrito dos principais fatos descobertos em uma pesquisa de qualquer tipo, nível ou modalidade. Uma característica primordial é a organização das informações em elementos pré-textuais, textuais e pós-textuais. A disposição dos elementos do relatório está simplificada na seguinte estrutura:

a) elementos pré-textuais: capa, folha de rosto, errata, folha de aprovação, dedicatória, agradecimentos, epígrafe, resumo em língua estrangeira, sumário, lista de ilustrações, lista de abreviaturas, lista de símbolos;

b) elementos textuais: introdução, desenvolvimento e conclusão;

c) elementos pós-textuais: referências, apêndices, anexo, glossário.

Os elementos que compõem o relatório do TCC dependem de suas finalidades, pois ele pode se referir a uma pesquisa acadêmica ou profissional. Como os trabalhos acadêmicos diferem muito entre si, não podemos falar em um roteiro rígido para elaboração de projetos de pesquisa. É necessário considerar os elementos essenciais que possibilitem a inclusão de itens inerentes à especificidade do trabalho investigativo. 


\section{Estrutura pré-textual}

Capa: contém os dados de identificação institucional, o nome do autor, o título do trabalho, o local e a data.

Folha de rosto: vem imediatamente após a capa, e, nela, aparece o nome completo do autor do trabalho; no centro da folha, o título do trabalho desenvolvido (em negrito, corpo do texto maior que o de todo o trabalho e letra maiúscula); logo abaixo, da metade da folha para a direita, aparece a explicação rápida da natureza do trabalho, nome da instituição, grau pretendido, área/linha de pesquisa, nome do orientador. Na parte inferior, escreve-se o nome da cidade onde o trabalho será apresentado e o ano. No verso da folha de rosto, situa-se a ficha catalográfica no caso de trabalho desenvolvido na pós-graduação lato e stricto senso.

Folha de aprovação: trata-se de item importante do trabalho. Seu conteúdo abrange: nome do autor e título como na capa, seguidos de local e data de aprovação. Em seguida, os nomes dos componentes da Banca Examinadora e as respectivas instituições a que pertencem; página de dedicatória, página de agradecimento e página de epígrafe não são obrigatórias.

Agradecimentos: visa agradecer às pessoas que contribuíram com o êxito do trabalho.

Resumo na língua vernácula: é elemento obrigatório do trabalho. Deve conter, de forma sintética, os objetivos, a metodologia empregada e as conclusões alcançadas. Após o resumo e na mesma página, devem aparecer as palavras-chave.

Resumo em língua estrangeira: é elemento do trabalho. Trata-se da versão para a língua estrangeira do resumo em língua vernácula.

Sumário: é onde aparece a estrutura do trabalho: os capítulos e seções com indicação das páginas iniciais.

Lista de ilustrações: ou lista de tabelas, de figuras, lista de símbolos, de abreviaturas e siglas. 


\section{Estrutura textual}

Corresponde à parte mais importante do trabalho, ao corpo do trabalho.

Introdução: é a apresentação do trabalho ao leitor, escrita pelo autor do trabalho. Pode haver a revisão bibliográfica a fim de situar o leitor quanto ao estudo do problema; explicita o conteúdo sintetizado de cada capítulo.

Desenvolvimento: compreende todos os capítulos. É uma das partes mais importantes do trabalho. "É onde se discute o problema principal e os secundários, decorrentes de sua explicitação. É aí que se verifica como se processou a discussão, como as soluções foram encontradas, como a metodologia proposta vai se realizando" (INÁCIO FILHO, 2003, p. 122).

Conclusão: é o fecho do trabalho, em que aparece a solução encontrada para o problema proposto. Contém a síntese da discussão. É o autor "[...] que conclui, fecha, termina seu texto, faz suas observações finais" (INÁCIO FILHO, 2003, p. 123).

\section{Estrutura pós-textual}

São quatro os elementos pós-textuais.

As referências: dizem respeito a qualquer tipo de fonte, bibliográfica ou não. Existem outras fontes não bibliográficas, como por exemplo, as obtidas por meio de entrevistas, questionários, arquivos e Internet.

Apêndice: consiste em texto elaborado pelo autor, visando a complementar sua argumentação. É identificado por letra maiúscula, travessão e respectivos títulos. Como exemplo de apêndice, citamos: formulários, roteiros de entrevista, roteiros de análise documental, protocolos de registro de observação etc.

Anexo: é um elemento opcional no trabalho e difere do apêndice por não ser escrito pelo autor do trabalho. Temos como exemplo: a LDBEN 9394/96, regulamentos, textos raros etc. 
Glossário: é também opcional, mas necessário quando o texto possui expressões técnicas de uso restrito que devem aparecer no glossário acompanhadas das respectivas definições.

\section{A relação orientador e orientando de TCC}

A proposta de atribuições para o orientador-orientando teve como referência a análise de Trabalhos de Conclusão de Cursos (TCC) dos alunos de uma instituição de ensino do Distrito Federal e consultas a autores na área. Não há intenção de unificar o processo de produção científica, e contemplam-se orientações que podem ser adaptadas aos diferentes tipos de TCC, disciplinas de metodologia científica e similares.

A relação entre orientador e orientando inovou-se nas últimas décadas, principalmente, com destaque à adoção de processo interpessoal de aprendizagem mútua e contínua, com nova configuração pessoal, horizontal, sem deixar de ser profissional. Estimula-se o desafio à criatividade e ao entendimento de que ambas as partes são autores de uma construção solidária.

A esse respeito, Viana (2007) menciona Zilbermann (2006) e cita a década de 1970 como o marco inicial da relação acadêmica horizontal entre orientador e orientando, fugindo aos moldes da relação vertical presente nas salas de aula dos diferentes níveis de ensino, no decorrer da história brasileira. Entre as características dessa horizontalidade, podem ser mencionados: a relação entre pessoas com hábitos; processos de estudo e níveis de conhecimento diferenciados; relação educativa orientada por objetivo comum; e o entendimento de que o bom relacionamento entre orientador e orientando define, em certo grau, a qualidade do TCC.

Essa relação pode ser caracterizada como uma parceria, um caminho de mão dupla, que exige o diálogo, a autonomia e o trabalho conjunto como qualidades necessárias. As partes interagem, respeitando a personalidade de cada um dos envolvidos. Ambos crescem em uma relação movida pela reciprocidade, pela interação dialética e pelo vínculo de confiança que se conquista à medida que a 
importância da orientação é percebida pelos orientandos, seja pelos avanços nos estudos, seja pela qualidade do trabalho.

Huguete (1994) tece considerações sobre dois fatores relacionados ao processo de geração de conhecimentos: competência metodológica do orientador e o seu relacionamento com os alunos. Nesse estudo, a autora apresenta as qualidades de um bom orientador, entre elas, as que contribuem para a explicitação da relevância do tema, a sua problematização e contextualização, o respeito à autonomia e a lógica de pensamento do orientando, o conhecimento das abordagens que podem ser aplicadas ao estudo, a transmissão do otimismo e o relacionamento profissional que atenda aos princípios da ética na relação orientador e orientando.

Em Machado (2002, p. 53), as preocupações dos orientadores em relação aos orientandos voltam-se para:

[...] os problemas de escrita, para a tendência de cópia e reprodução e para a dificuldade de criar, mostrar audácia e autonomia, características, estas últimas, que consideram bem-vindas para um pesquisador. Abordam as relações afetivas entre orientador e orientando, muitas vezes apontando para as necessidades de superar a excessiva dependência que facilmente se instala, neste último, com relação ao primeiro. Referem-se, também, ao entrelaçamento dos problemas afetivos com a vida pessoal, às vivências e experiências do autor e também se ocupam de delinear e discutir as diferenças entre as funções do professor e pesquisador na busca de uma definição para o papel do orientador.

O orientador preconizado neste documento tem o papel de educador. A sua experiência mais amadurecida interage com a experiência em construção do orientando; cabe-lhe atuar como guia e como aprendiz da própria prática, passando ao orientando o sentimento de estarem juntos e a sua predisposição para desenvolver o TCC de forma segura e tranquila. Caminham juntos na busca do saber e da maturidade. Sua competência alarga-se à medida que as experiências vividas com os orientandos desvelam outros espaços para pesquisas.

O orientando, com a colaboração do orientador, descobre os caminhos a serem trilhados no trabalho. É responsável pelas suas escolhas, o que lhe requer o 
exercício da criticidade necessária para garantir a qualidade. A retribuição esperada do orientando é o compromisso e a responsabilidade no desenvolvimento do trabalho.

Viana (2007, p. 5) registra, ainda, que:

Competências técnicas, teóricas e políticas devem ser aliadas à afetividade, traduzida em carinho sem paternalismo, apoio sem assistencialismo, mas que estabeleça um vínculo de confiança em que a criticidade do orientador em relação à produção do orientando seja vista como uma contribuição para a qualidade do trabalho. Cabe ao orientando, por sua vez, ter compromisso e responsabilidade, desenvolver uma pesquisa que seja parte de seu projeto de vida e que tenha continuidade.

Compete ao orientando ser crítico de sua produção, ter disposição para ler, reler, fazer e refazer o texto quantas vezes forem necessárias, ser autônomo, ser ético na pesquisa, ser apaixonado e seduzido por seu objeto, estabelecer sintonia com o orientador, sem subserviência, entre outros aspectos. Mediante essas considerações, pode se afirmar que se trata de relação essencialmente educativa, voltada para assegurar que as dimensões didático-pedagógica e dialógico-afetiva estejam presentes no processo de produção do TCC. A seguir, serão detalhadas as atribuições do orientador e do orientando.

\section{Atribuições do orientador}

- Pautar-se nas orientações da política institucional, do projeto pedagógico do curso e das normas específicas.

- Ser especialista na área em que atua como orientador.

- Submeter ao Conselho de Ética as pesquisas com seres humanos.

- Compreender a importância do TCC para a busca da qualidade necessária à formação, estimulando pesquisas voltadas à investigação do próprio curso.

- Entender o papel do orientador numa relação de cumplicidade, de respeito, estabelecendo vínculos de confiança, sem paternalismos. 
- Transmitir crença e otimismo ao orientando.

- Respeitar a autonomia do orientando, fazendo do diálogo a base dessa relação caracterizada pela responsabilidade compartilhada.

- Orientar a escolha do tema, respeitando, na medida do possível, o interesse do orientando.

- Discutir o problema da pesquisa para verificar a clareza e a viabilidade em relação à problematização, à contextualização, à explicitação da relevância do tema e objetivos.

- Sugerir leituras que esclareçam as alternativas teóricas sobre o objeto de estudo.

- Definir com os orientandos os estudos e as pesquisas necessários, identificando os elementos básicos e a sua articulação com as linhas de pesquisas.

- Compatibilizar o tempo e a adequação da pesquisa a propósitos, amostras e análises.

- Orientar quanto aos processos de registro e documentação de conceitos e categorias fundamentais, com vistas à racionalização dos estudos.

- Orientar o detalhamento de todas as etapas da pesquisa.

- Acompanhar, sistematicamente, o desenvolvimento do TCC, fazendo as apreciações necessárias à continuidade dos estudos e à reorientação dos mesmos.

- Exigir rigor metodológico e fidedignidade aos conteúdos, sugerindo a procura de especialista, quando for o caso.

- Evitar assumir as tarefas do orientando, ante o risco de passar-lhe a impressão de falta de confiança.

- Chamar a atenção do orientando para a coerência, presença de generalidades, retórica do texto, imprecisão e ambiguidade dos conceitos.

- Explicitar aos orientandos a sistemática e os critérios de avaliação do TCC.

- Selecionar a banca examinadora em conjunto com os orientandos, quando for o caso. 
- Presidir a banca examinadora, conduzir os debates, o processo de avaliação e a comunicação dos resultados.

- Evitar levar o orientando à defesa, sem ter certeza da aprovação do trabalho pela banca.

- Comunicar ao setor competente os casos de não conclusão do TCC, para as medidas cabíveis e o acompanhamento de prazos.

O orientador não pode perder de vista o propósito de levar o orientando até onde ele pode ir, respeitando os limites mínimos de qualidade, as suas potencialidades e a lógica de pensamentos evidenciados no trabalho. A verdade tem que ser constante tanto na indicação de pontos a serem aprimorados, como no reconhecimento de méritos.

\section{Atribuições do orientando}

- Comparecer às sessões de orientação, conforme cronograma de trabalho.

- Manifestar ao orientador o interesse pelo estudo, sendo fiel a crenças e convicções.

- Assumir, com competência, segurança e autonomia, a criação intelectual.

- Manifestar, em sua conduta, a confiança na experiência e na integridade intelectual do orientador, evitando comportamentos de desinteresse e impaciências.

- Produzir trabalho relevante para a área de formação.

- Manter relacionamento cordial e profissional com o orientador, manifestando-o em sua conduta.

- Verificar, cuidadosamente, o projeto de estudo, para identificar o seu valor social e a importância no enriquecimento da formação.

- Realizar, cuidadosamente, a revisão teórica, em termos de conteúdos e autores que sustentam as fases conceitual e teórica.

- Expressar ideias e concepções de forma clara, predispondo-se a modificá-las mediante as argumentações do orientador. 
- Ater-se aos conteúdos essenciais ao TCC, sem perder-se em grandes retomadas históricas e contextualizações.

- Considerar o tempo disponível ao projeto para definir o problema de estudo, as hipóteses, a metodologia e os instrumentos necessários.

- Observar os padrões da apresentação científica em conformidade com a ABNT.

- Compreender que a troca de experiências e o diálogo favorecem o enriquecimento da relação entre orientador e orientando.

- Seguir, sistematicamente, todos os passos definidos no projeto para o desenvolvimento do trabalho, procurando entender a importância para o alcance dos objetivos.

- Assegurar a coerência teórica e a fidedignidade do TCC, evitando recortes de teorias desarticuladas, divagação teórica e plágio.

- Exteriorizar as dúvidas e as divergências que possam ocorrer no decorrer do trabalho, abrindo canais para o diálogo com o orientador.

- Dialogar sobre o trabalho, predispondo-se a aceitar os direcionamentos do orientador.

O sucesso do orientando é maior quando vê o seu esforço retribuído por comportamentos, como o atendimento periódico do orientador, a leitura e a discussão de seus textos. A avaliação, seja sob a forma de autoavaliação e ou avaliação cooperativa, deve estar presente no processo de orientação, contribuindo para maximizar os resultados do processo e do produto do TCC. Espera-se concorrer para a formação de um profissional seguro, estimulado e confiante na sua capacidade de gerar conhecimentos.

\section{Considerações finais}

Tomando por base a literatura especializada, pontuamos neste texto elementos relevantes à elaboração de um projeto de pesquisa. São posicionamentos que, no meio acadêmico, constituem-se em objeto de consulta para esclarecer questões relativas ao processo de criação de um Trabalho de Conclusão de Curso. 
É responsabilidade da instituição de ensino superior definir o tipo de trabalho a ser exigido do aluno, assim como estabelecer as normas para a sua execução e apresentação. Nessa tomada de decisão, há que se considerar as necessidades e especificidades dos cursos de graduação, sem perder de vista que o trabalho de investigação científica a ser realizado pelo aluno, independentemente da área de conhecimento abordada, não deve realizar-se de forma espontânea ou intuitiva.

Assim, a proposta desse tempo-espaço formativo é favorecer a construção de trabalhos acadêmicos, que se submetem aos padrões da produção científica no momento em que se proporciona ao aluno a oportunidade de potencializar e sistematizar as habilidades e os conhecimentos adquiridos ao longo de sua formação.

\section{Final paper course: time-formative space}

\section{Abstract}

The study focuses on the importance of the Conclusion Course Task-TCC, as an academic exercise correlated to the area of students training at higher education, performed at some time during the course. It is a compulsory curricular activity, with a scientific nature in the knowledge area, which supports the graduate course that its linked. The TCC is a research activity which means dialogue to the reality in an organized and objective system, in order to provide answers to the real problems. Teachers and students, when develop the investigations of the conclusion of the course, need to be aware of the ethical issues throughout the process.

Keywords: Academic formation. Final paper course.

\section{Referências}

ARAÚJO, J. C. S. Para uma análise das representações sobre as técnicas de ensino. In: VEIGA, I. P. A. (Org.). Técnicas de ensino: por que não? 17. ed. Campinas: Papirus, 2006. 
BARROS, A. de J. P.; LEHFELD, N. A. de S. Projeto de pesquisa: propostas metodológicas. 14. ed. Petrópolis: Vozes, 1990.

DEMO, P. Introdução à metodologia da ciência. São Paulo: Atlas, 1985.

HAGUETTE, T. M. F. Universidade: nos bastidores da produção de conhecimento. In: BIANCHETTI, L.; MACHADO, Ana Maria Netto (Org.). A bússola do escrever: desafios e estratégias na orientação de teses e dissertações. Florianópolis: UFSC; São Paulo: Cortez, 2002.

INÁCIO FILHO, G. A monografia dos cursos de graduação. 3. ed. Uberlândia: Edufu, 2003.

LAKATOS, E. M.; MARCONI, M. de A. Metodologia científica. 2. ed. São Paulo: Atlas, 1991.

LANKSHEAR, C.; KNOBEL, M. Pesquisa pedagógica: do projeto à implementação. Porto Alegre: Artmed, 2008.

MACHADO, Ana Maria Netto. A relação entre a autoria e a orientação no processo de elaboração de teses e dissertações. In: BIANCHETTI, Lucídio; MACHADO, Ana Maria Netto (Org.). A bússola do escrever: desafios e estratégias na orientação de teses e dissertações Florianópolis: UFSC; São Paulo: Cortez, 2002. p. 25-37.

MORIN, E. et al. Idéias contemporâneas. São Paulo: Ática, 1989.

OLIVEIRA, S. L. Tratado de metodologia científica. São Paulo: Pioneira, 1997.

PÁDUA, E. M. M. Metodologia da pesquisa: abordagem teórica-prática. Campinas: Papirus, 1996.

RIOS, T. A. A dimensão ética da aula ou o que nós fazemos com eles. In: VEIGA, I. P. A. (Org.) Aula: gênese, dimensões, princípios e práticas. Campinas: Papirus, 2008. p.73-93.

RUDIO, F. V. Introdução ao projeto de pesquisa científica. 23. ed. Petrópolis: Vozes, 1986.

SANTOS, B. S. Introdução a uma ciência pós-moderna. Rio de Janeiro: Graal, 1989.

SANTOS, B. S. Um discurso sobre as ciências. 7. ed. Porto: Afrontamento, 1995. 
SEVERINO, J. A. Metodologia do trabalho científico. 23. ed. São Paulo: Cortez, 2007.

SILVEIRA, D. C. A exigência ética da educação. Revista FilosoFAZE, Passo Fundo, v. 1, n. 1, p.12-21, 1992.

VASQUEZ, A. S. Filosofia da práxis. 2. ed. Rio de Janeiro: Paz e terra, 1977.

VEIGA, I. P. A. Educação básica e educação superior: projeto político pedagógico. 2. ed. Campinas: Papirus, 2007.

VIANA, Cleide Maria Quevedo Quixadá. Desafios no processo de elaboração de dissertações e teses: um olhar na relação orientador-orientando: relatório técnico de Pós-Doutorado em Educação. Brasília: UnB, 2007.

ZILBERMANN, Regina. Orientação: a aventura compartilhada. In: BIANCHETTI, Lucídio; MACHADO, Ana Maria Netto (Org.). A bússola do escrever: desafios e estratégias na orientação de teses e dissertações. Florianópolis: UFSC; São Paulo: Cortez, 2002. p. 46-61. 


\section{Para publicar na revista Universitas Humanas, acesse 0 endereço eletrônico www.publicacoesacademicas.uniceub.br. Observe as normas de publicação, para facilitar e agilizar o trabalho de edição.}

